Bond University

Research Repository

\title{
Accuracy of diagnosis of pterygium by optometrists and general practitioners in Australia
}

Hirst, Lawrence W.; Smith, Jane W

Published in:

The Australian journal of optometry

DOI:

$10.1111 / \mathrm{cxo} .12916$

Licence:

Other

Link to output in Bond University research repository.

Recommended citation(APA):

Hirst, L. W., \& Smith, J. W. (2020). Accuracy of diagnosis of pterygium by optometrists and general practitioners in Australia. The Australian journal of optometry, 103(2), 197-200. https://doi.org/10.1111/cxo.12916

\footnotetext{
General rights

Copyright and moral rights for the publications made accessible in the public portal are retained by the authors and/or other copyright owners and it is a condition of accessing publications that users recognise and abide by the legal requirements associated with these rights.
}

For more information, or if you believe that this document breaches copyright, please contact the Bond University research repository coordinator. 
RESEARCH

Accuracy of diagnosis of pterygium by optometrists and general practitioners in

Australia

Lawrence W Hirst* DSc, MD, MPH, MBBS (Hons), DO, FRANZCO, AM

Jane Smith† MBBS, FRACGP

*The Australian Pterygium Centre, Brisbane, Australia: Department of Surgery,

University of Queensland, Brisbane, Australia: Queensland Eye Institute, Brisbane,

Australia

† Bond University Medical Program, Gold Coast, Australia

Running title: accuracy of pterygium diagnosis

Key words: accuracy, diagnosis, pinguecula, pterygium 
Background: It was the author's (LWH) observation that pterygium was misdiagnosed frequently by general practitioners that led to this study. The aim was to identify the rate of misdiagnosis of pterygium by optometrists and general practitioners based upon assessing referral accuracy to a single ophthalmologist $(\mathrm{LWH})$.

Methods: This study involved a prospective case series from $25^{\text {th }}$ March 2015 to the $18^{\text {th }}$ December 2018 in a tertiary referral practice specialising in pterygium. The accuracy of diagnosis of pterygium, based upon the content of the clinical referral, was undertaken for optometrists and general practitioners. The benchmark for diagnostic accuracy was the diagnosis made by the author (LWH) during a consultation in person by the author (LWH) using a hand-light examination and confirmed by slit-lamp examination.

Results: A total of 1511 consecutive patients were included in the study with $90 / 549$ incorrectly diagnosed (16\%) by general practitioners and 14/962 (1.4\%) by optometrists. General practitioners were 13.28 times more likely to incorrectly diagnose a pterygium than optometrists (95\% Cl: 7.48-23.57).

Almost exclusively, the incorrect diagnosis made by general practitioners was naming a pinguecula, a pterygium. The same misdiagnosis was made by optometrists but far less frequently.

Conclusion: General practitioners misdiagnosed pterygium far more often than optometrists which may reflect a reduction in training in eye health. 
The provision of primary eye care, which includes detection, diagnosis and management of anterior and, posterior segment conditions as well as neuroophthalmic disorders, has been undertaken by both general practitioners and optometrists who will then refer to ophthalmologists when surgical treatment of a patient is required. Fifteen years ago optometrists were granted therapeutic privileges ${ }^{1}$ which has swung the balance of primary eye health care to the optometric profession. Medicare statistics ${ }^{2,3}$ show a trend of increasing provision of optometric services at a rate much greater than the increase of all services by general practitioners. BEACH (Bettering the Evaluation and Care of Health) data shows a drop in general practitioner eye related consultations of $15 \%$ over about the past decade, with cataract, glaucoma, diabetic retinopathy being the most commonly seen chronic conditions ${ }^{4}$ and conjunctivitis, eyelid problems and foreign bodies being the most commonly encountered acute eye problems ${ }^{5}$. It is possible that the availability of specialised equipment such as slit-lamps, tonometers, indirect ophthalmoscopes, and OCT ( optical coherence tomography) which are now regularly used by optometrists may have increased the scope of examinations, investigations, and diagnoses that are undertaken in optometric offices. Perhaps it is also related to changes in medical and optometric education. Optometrists, like general practitioners are also very likely to refer patients to an ophthalmologist if their therapeutic intervention has been unsuccessful, or if surgery is more appropriate or if an ophthalmic or surgical opinion is needed.

One of the diagnoses that will frequently present to both general practitioners and optometrists will be a lump on the nasal area of the eye in the interpalpebral zone near the nasal limbus (pinguecula) or over the nasal limbus and onto the cornea (pterygium) (Figures 1 and 2). Both of these conditions can also occur on the 
temporal aspect of the eye, although far less frequently. Distinguishing between these two conditions is crucial as a pterygium has the potential to significantly interfere with vision, while a pinguecula never causes visual problems.

General practitioners or optometrists are likely to refer a correctly diagnosed pterygium to an ophthalmologist because of symptoms such as vision changes, discomfort, growth of the pterygium, cosmetic concerns or because the patient demands a review, or the referrer believes that surgical intervention may be required.

These are extremely common with prevalence rates of $7 \%$ for pterygium ${ }^{6}$ and nearly $70 \%$ for pingueculae ${ }^{6}$ of a random sample of the population of the Blue Mountains and so are likely to be seen by all optometrists and general practitioners every day.

The aim of this research was to examine the accuracy of diagnosis of such lumps in patients where a referral for possible treatment was considered necessary or possible by both general practitioners and optometrists in Australia. This study cannot assess the likelihood of a correct diagnosis by these two groups of referrers for more subtle or difficult diagnoses and also cannot address the accuracy of diagnosis by general practitioners when the patient is referred to an optometrist or an ophthalmologist other than the author $(\mathrm{LWH})$.

\section{METHODS}

Approval for this study was obtained from the Human Research Ethics Committee of the Royal Australian and New Zealand College of Ophthalmologists. No funding for this project was obtained and the authors had full access to all of the data in this study. 
The author (LWH) accepts only patients diagnosed with a pterygium or pinguecula from general practitioners, optometrists and ophthalmologists. All patients referred to this practice were examined by the author and a diagnosis made of pterygium or pinguecula which was recorded in a database against the diagnosis made by the referrer in the referral letter between $25^{\text {th }}$ March 2015 and $18^{\text {th }}$ December 2018. A pterygium was diagnosed firstly, by a hand-light examination, and then confirmed by slit-lamp examination. The sentinel finding is the growth of a fibrovascular membrane across the limbus, usually arrowhead in morphology ${ }^{7}$, and usually from the nasal conjunctiva although occasionally from the temporal conjunctiva, and always in the interpalpebral zone (Figure 1). Growth of this lesion further onto the cornea can cause visual loss by astigmatism or intrusion into the visual axis.

Pterygia may cause irritation and can be a significant cosmetic blemish. The only way to deal with this condition definitively is by surgical removal.

Similarly, a pinguecula was firstly diagnosed by hand-light examination and confirmed by slit-lamp examination. A pinguecula is a stationary usually yellowish lump ${ }^{6}$ in the nasal and often in the temporal conjunctiva in the interpalpebral zone which may or may not be inflamed with congested vessels (Figure 2). This never causes visual loss and never crosses the limbus. This condition virtually never needs surgical removal.

Note that the sentinel differentiating point between these two lesions is with respect to whether the lesion crosses the limbus which is readily recognised by a hand-light examination alone. 
The results of the "true diagnosis" as ascertained by the author (LWH) and the referrer's diagnosis was analysed with a two by two table and confidence intervals calculated.

Although optometrists are likely to use a slit lamp to confirm a diagnosis of pterygium, general practitioners are most likely to use a hand-light plus or minus some magnification by a loupe, or direct ophthalmoscope examination to establish their diagnosis.

Statistical method:

As the outcome measure is binary i.e. correct versus incorrect diagnosis, a logistic regression was used. The optometric results were used as the baseline in the general practitioner variable, so the odds ratio was for an incorrect diagnosis by a general practitioner relative to an optometrist.

\section{RESULTS}

Between $25^{\text {th }}$ March 2015 and $19^{\text {th }}$ December 2018 a total of 1511 new patient referrals were received from optometrists and general practitioners. There was a total referral base of 497 general practitioners and 962 optometrists in this study. The reason for referral was usually either patient irritation, possible visual impairment or patient's concerns about the aesthetic appearance of the eye. The hand-light examination diagnosis, without any magnification, of pterygium or pinguecula, was made in every patient and confirmed by slit-lamp examination by the author (LWH).

Table 1 shows the distribution of referrals and the number of incorrect diagnoses.

In only two patients was an incorrect diagnosis made where the referral source was the same general practitioner. 
A total of 1511 consecutive patients were included in the study with 90/549 incorrectly diagnosed (16\%) by general practitioners and 14/962 (1.4\%) by optometrists. In all cases the incorrect diagnosis by general practitioners and optometrists was calling a pinguecula, a pterygium.

The difference in the percentage of incorrect diagnoses between general practitioners and optometrist was $14.6 \%$ Table 2 defines the odds ratios and confidence intervals. In summary, the general practitioners were 13.28 (95\% Cl $7.48-$ 23.57) more likely to incorrectly diagnose a pterygium compared to optometrists. ( $p<$ $.0005)$

Tables 3 and 4 show the number of patients referred by individual general practitioners and optometrists. Table 3 shows that single general practitioners most often referred only one patient during the study period therefore indicating that the diagnostic error rate was not unduly influenced by multiple referrals from single practitioners all with an incorrect diagnosis. On the other hand Table 4 demonstrates that optometrists often referred more than one patient during the study period which reinforces the accuracy of diagnosis by optometrists. If single optometrists mistakenly diagnosed a pterygium then this would have a considerable influence on the total optometric diagnostic error rate.

\section{DISCUSSION}

The diagnosis of pterygium is straight forward and can be made by a hand-light examination available to all referral sources. The addition of more expensive equipment such as a slit-lamp is unnecessary for the basic diagnosis. 
Optometrists spend 5-7 years in primary eye health care and general practitioners train for 4-6 years in medicine followed by another 4 years in post-graduate training in general practice. The time devoted to ophthalmic education during medical training has been diluted by competing curricula, resulting in fewer ophthalmic skills acquired by current medical graduates ${ }^{8,9}$.

Until 2011, the Royal Australian College of General Practitioners curriculum contained two pages relating to eye conditions compared to the 2016 version where there is only a sentence about eye procedures ${ }^{10}$. This indicates a dramatic decrease in exposure to eye conditions for general practitioners in training. Therefore, one could attribute the reason for the relative failure of general practitioners to correctly diagnose a pterygium is likely to be the result of inadequate training of medical graduates or general practitioners in the area of ophthalmology 8,9 . However, it should be noted that the error in diagnosis relates only to patients for whom the referral sources thought consideration for treatment might be appropriate. It is likely, but not proven, that patients with pterygia not considered for referral, would be smaller or less problematic and therefore perhaps, they might indeed be more difficult for a general practitioner to diagnose than those that were actually referred.

The community optometrist is now probably the central primary eye health care provider according to MBS data on optometric services provided ${ }^{2}$. The ready availability to refer ocular problems to an optometrist is reinforcing the concept that ophthalmic knowledge is no longer really needed for general practitioners ${ }^{1,11}$. Furthermore,BEACH data shows a small drop in the number of eye problems presenting to general practitioners from $2.5 \%$ to $2.1 \%$ of all consultations over the last 10 years $^{4} .2016 \mathrm{BEACH}$ reports $^{4,12} 37 \%$ of general practice referrals were to allied health professionals of which $2 \%$ were to optometrists. This suggests that 
$0.1 \%$ of all general practitioner encounters results in a referral to an optometrist, but this data does not include general practitioner recommendations for a patient to see an optometrist, without a referral.

Overall $0.7 \%$ of all general practitioner encounters result in a referral to an ophthalmologist, mostly for cataract, diabetes and visual disturbance ${ }^{12}$. However, this may mean that where the ocular examination is critical to the evaluation of the general health of the patient, the general practitioner may have increasing diffidence and difficulty in providing that ocular examination, for example in the diabetic patient or a patient with headaches where the optic disc evaluation is essential. The relative difficulty of general practitioners to diagnose a simple condition such as pterygium, raises serious concerns that more subtle conditions or those that require greater skills, such as ophthalmoscopy, may be misdiagnosed or missed entirely. It is critical that general practitioners remain confident and competent in the use of the ophthalmoscope. If general practitioners all owned an ophthalmoscope and were trained to use this as a magnification and illumination instrument to examine the anterior segment then perhaps the misdiagnosis rate would have been less. To support this, all medical students should own and use an ophthalmoscope to examine multiple patients' eyes during their training period, additionally postgraduate training has been shown to enhance general practitioners' ophthalmic skills ${ }^{11}$.

This study highlights what appears to be deficiencies in general practitioner training but it should be emphasised that optometrists who focus their education of the eyes, are competent to undertake more of the load of diagnosis and treatment of ocular conditions. Probably the "best of both worlds" is the active collaboration and 
cooperation between general practitioners and optometrists in the best interest of all patients.

It will remain up to the Australian Medical Council, Medical Schools, and the Royal Australian College of General Practitioners, to decide the importance of training in the basic ophthalmic examination techniques and diagnostic skills.

On the other hand, this study highlights that optometrists performed very well in making the correct diagnosis of a pterygium.

This study does have limitations specifically that the "gold standard" diagnosis has been made by only one ophthalmologist, however, this ophthalmologist is the only one in Australia to restrict their practice to pterygium alone and therefore is likely to be appropriate as the person to define the correct diagnosis of pterygium.

As well, the ophthalmologist expert was not masked to the type of referrer as this was a clinical study where the patient's welfare required the ophthalmologist to recognise the referrer, and this could result in a degree of confirmation bias.

Acknowledgement: We wish to thank Schuyler Waynforth for her statistical analysis.

\section{REFERENCES}

1. Kiely PM, Cappuccio S, Mclntyre E. Optometry Australia Scope of Practice Survey 2015. Clinical and Experimental Optometry. Volume 100, issue 3, p260269

2. Australian Government Departments of Human Services, Medicare Australia, Statistics, Medicare Item Reports, accessed August/November 2018; http://medicarestatistics.humanservices.gov.au/statistics/mbs 
3. Australian Institute of Health and Welfare 2018. Australia's health 2018. Australia's health series no. 16. AUS 221. Canberra: AlHW

4. Britt H, Miller GC, Bayram C, Henderson J, Valenti L, Harrison C, Pan Y, Charles J Pollack AJ, Chambers T, Gordon J, Wong C. A decade of Australian general practice activity $2006-07$ to $2015-16$. General practice series no. 41 . Sydney: Sydney University Press, 2016

5. Morgan S, Tapley A, Henderson KM, Spike NA, McArthur LA, Stewart R, et al. Australian general practice trainees' exposure to ophthalmic problems and implications for training: a cross-sectional analysis. J Prim Health Care. 2016;8(4):295-302.

6. Panchapakesan J, Hourihan F, Mitchell P. Aust N Z J Ophthalmol. 1998;26 Suppl:S2-5.

7. Krachmer JH, Palay DA. Cornea Atlas. Elsevier $4^{\text {th }}$ Edition, 2014; 187

8. Zhang HH, Hepschke JL, Shulruf B, Francis IC, Spencer SK, Coroneo M, et al. Sharpening the focus on ophthalmology teaching: perceptions of medical students and junior medical officers. Clin Exp Ophthalmol. 2018;46(9):984-93.

9. Green C. Sharpening the focus on ophthalmology teaching: has anything changed? Clin Exp Ophthalmol. 2018;46(9):981-3.

10. The Royal Australian College of General Practitioners. Curriculum for Australian General Practice 2016 - CS16 Core skills unit. East Melbourne, Vic: RACGP, 2016. https://curriculum.racgp.org.au/

11. Jackson C, De Jong I, Schluter P. Changing clinician practice. The RACGP/RACO National GP Eye Skills Workshop. Health Policy. 2002 AFP 31, 285-90 
12. .Britt H, Miller GC, Henderson J, Bayram C, Harrison C, Valenti L, Pan Y, Charles J, Pollack AJ, Wong C, Gordon J. General practice activity in Australia 2015-16. General practice series no. 40. Sydney: Sydney University Press, 2016.

Corresponding Author:

Professor Lawrence Hirst

lawrie@tapc.net.au 


\section{Table 1}

\section{Diagnostic accuracy}

\begin{tabular}{|l|l|l|}
\hline Referral Source & $\begin{array}{l}\text { General } \\
\text { Practitioner }\end{array}$ & \\
\hline Total number of & 459 & 948 \\
patients referred & & \\
\hline Incorrect diagnosis & 90 & 14 \\
\hline Percentage incorrect & $16 \%$ & $1.45 \%$ \\
\hline
\end{tabular}


Table 2

Logistic regression

$\begin{array}{lll}\text { Number of observations } & = & 1511 \\ \text { Logistic regression chi2 }(1)= & 121.22 \\ \text { Probability }>\text { chi2 } & =- & 0.00 \\ \text { Pseudo R2 } & = & 0.16\end{array}$

Log likelihood $=-318.046$

\begin{tabular}{|c|c|c|c|c|c|}
\hline Diagnosis & $\begin{array}{l}\text { Odds } \\
\text { Ratio }\end{array}$ & Std. Error & $z$ & $P>|z|$ & $\begin{array}{l}\text { [ 95\% Confidence } \\
\text { Intervals] }\end{array}$ \\
\hline $\begin{array}{l}\text { General } \\
\text { practitioners }\end{array}$ & 13.28 & 3.89 & 8.83 & 0.000 & 7.48 to 23.57 \\
\hline $\begin{array}{l}\text { Estimated } \\
\text { baseline } \\
\text { odds }\end{array}$ & 5.1 & 0.59 & 14.13 & 0.000 & 4.07 to 6.39 \\
\hline
\end{tabular}


Table 3

Frequency of patient referrals by individual general practitioners

\begin{tabular}{|l|l|l|l|}
\hline ONE PATIENT & TWO PATIENTS & $\begin{array}{l}\text { THREE } \\
\text { PATIENTS }\end{array}$ & FOUR PATIENTS \\
\hline 446 & 43 & 3 & 5 \\
\hline
\end{tabular}


Table 4

Frequency of patient referrals by individual optometrists

\begin{tabular}{|l|l|l|l|l|l|l|l|}
\hline ONE & TWO & THREE & FOUR & FIVE & SIX & SEVEN & EIGHT OR \\
PATIENT & PATIENTS & PATIENTS & PATIENTS & PATIENTS & PATIENTS & PATIENTS & $\begin{array}{l}\text { MORE } \\
\text { PATIENTS }\end{array}$ \\
\hline 328 & 228 & 123 & 84 & 55 & 48 & 28 & 68 \\
\hline
\end{tabular}


Figure 1

External photograph of a nasal pterygium which is crossing the limbus (arrows)

Figure 2

External photograph of a nasal pinguecula which respects the limbus 